\title{
Modern system of strategic management of the organizations of fuel-and-energy complex in Russia
}

\author{
Daria Maksimova ${ }^{1, *}$ \\ ${ }^{1}$ Moscow State University of Civil Engineering, 129337, 26, Yaroslavskoye Shosse, Moscow, Russia
}

\begin{abstract}
Studying the modern legislation and law-enforcement practice allows the author to reveal some relevant problem aspects of the system of strategic management in the organizations of fuel-and-energy complex of the Russian Federation. The increase in the efficiency of the solution of problem aspects can be reached mainly due to the introduction of the integrated approach to the system of the strategic management. The problem aspects of the creation of the general scheme and development of the industry development strategy of the Russian organizations, which are the fundamental prerequisites for the creation of dynamic system of strategic management, were revealed during the research.
\end{abstract}

\section{Introduction}

The global transformational processes exert a great impact on the current state of functioning and development of the activity of the reorganizations of the fuel-and-energy complex of the Russian Federation. Development of fuel-and-energy complex of the Russian Federation, according to the experts consists of the universal use of renewables (renewable sources of energy, RSE) which will have occupied more than a quarter of the world market of energy by 2100, significantly surpassing the thermonuclear energy. Such a sharp transition to RSE will be caused by the gradual decrease in the extraction of hydrocarbons and reorientation of construction on any net energy capacities. According to the preliminary experts' estimates, the Russian Federation will take the leading position in the world market of energy.

The influence of the Russian Federation on the world market of energy will have made $21 \%$ by 2035 (the second position of the world ranking, after the United States of America $[1,2]$. It is important to note that the expert forecast considers the interdependence of high cost of the use of RSE and the high competition with hydro carbonic and nuclear energy in the market. Then according to the experts opinion "The forecast of scientific and technological development of branches of fuel-and-energy complex of Russia until 2035" claims that "the most powerful contribution to the decrease in level of consumption of oil will be made by the accelerated development of technologies of energy generation on the basis of RSE. The essential growth of the RSE share in the world volume of energy generation

\footnotetext{
*Corresponding author: Kosti4eva.daria@yandex.ru
} 
is predicted. RSS can bypass gas as the energy carrier in energy generation, and by 2035 RSE will have been able to come out on top" [3]. However, while there is a formation of technologies of energy generation based on RSE, it is necessary to pay attention to the influence of traditional types of resources to productions of the Russian organizations of fueland-energy complex of the Russian Federation. Therefore, because of the fact, it is necessary to strengthen the system of strategic management for traditional types of the resources, which are used in the fuel-and-energy complex of the Russian Federation.

The author of the research is convinced that the Russian energy branch demands more effective use of the available technological resources, as well as the decrease in the share of hydrocarbons and some technological improvement. That will accelerate the social-andeconomic development of branch in the future (up to 2050).

As global transformational processes are inseparably linked both with the advent of external and internal threats, and new opportunities of the system of strategic management, it is necessary to comprehend how to strengthen the position in the developed energy market of the Russian Federation, to adapt the systems of production and management to dynamic changes of the external environment, to exercise continuous, system strategic control by the means of technological improvement of activity of the Russian organizations. It is important to note that the global transformational processes contributed to the development of modern technologies without proper volume and quality of the resource base [4, 5]. As for the activity of the Russian organizations, functioning and developing in branches of fuel-and-energy complex of the Russian Federation, the continuous improvement of technologies has to be the prevailing direction of strategic management of the organizations' activity.

\section{Methods}

Nowadays we can observe aggravated problems of the development of the activity uniform heat-supplying organizations (UHSO), the heat-supplying organizations and heating systems within improvement target model of the development of the market of heat, detailed at the disposal of the Government of the Russian Federation "On the Energy strategy of the Russian Federation until 2030" and the strategy of sustainable development of UHSO, the heatsupplying organizations and heating systems to which the relevance the close attention in the system of the normative legal acts regulating branch of heat supply of the Russian Federation $[6,7,8]$.

We will analyze some modern problems of the UHSO activity, noted as prevailing ones in the branches of heat-supply of the Russian Federation in the state priorities of social and economic development: high wear of processing equipment in combined heat and power plant, boiler rooms, thermal losses, increasing in the heating systems every year and low efficiency of sources of thermal energy (Fig. 1).

Some documents point out only the size of income, which the state will receive as a result of the project implementation. Other documents, mark out also social efficiency of projects besides the budgetary efficiency.To confirm this fact the author offer the state-of-the-art review of the modern situation at the heat supply facilities during autumn and winter period of $2017-2018$.

The experts agree in opinion on the lack of financing of the UHSO activity, aimed at the maintenance of technological process in the conditions of high wear of the equipment and the delay of payments from the consumers [10], presented, shown in the figure 2. 


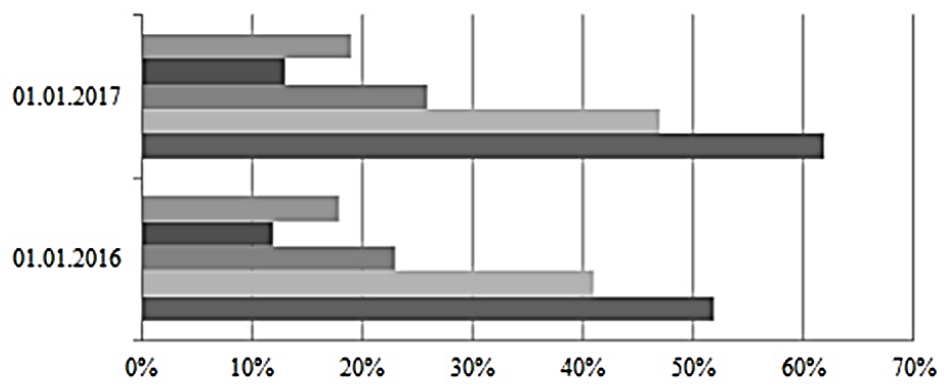

घ: Insufficient demand in the domestic market

घ: Uncertainty of an economic situation

घ: Lack of financial resources
- Lack of skilled workers

= Wear and lack of the equipment

Fig. 1. Modern problems of the UHSO activity

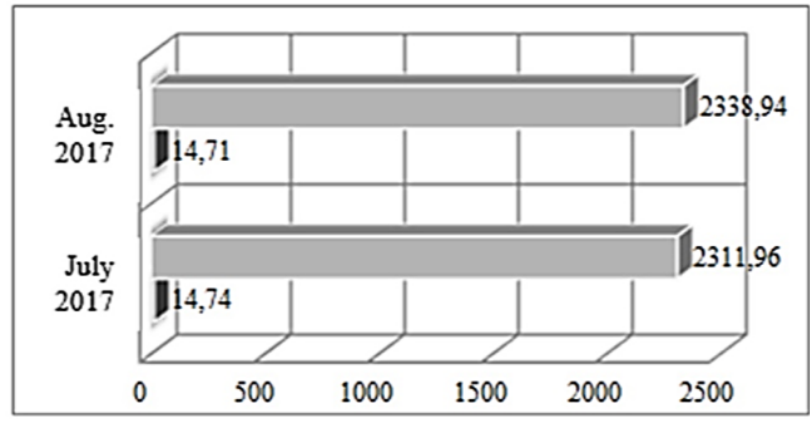

Fig. 2. Debt on the obtained credits and loans in the sector "Providing with electric energy, gas, steam; conditioning"

\section{Results}

The analysis of the Russian practice allowed pointing out the complex of the interconnected problems of the UHSO activity:

1. The divergence in settlings with the population for the heat delivery. Dishonesty of the consumers of services, which leads to the receivables without sources of their repayment.

2. Flexible division of responsibility between different branches of federal and executive authorities regarding settlings between consumers with suppliers of heat. It is dictated by some principles, contradicting each other that means the lack of a uniform method of settlings between consumers and USHO.

3. Illogicalness of the UHSO activity and the guaranteeing supplier. There is the requirement of search of other levers of the UHSO influence and the guaranteeing supplier. It is obvious that the UHSO activity has to be directed to leveling and neutralization of the arising technologic and economic problems and to have strategic focus on the technological development that confirms the need of strategic management of the UHSO activity.

At the same time, it is important to consider the managerial methods of the solution of the arising problems, which are already applied in practical activities of UHSO. In this regard, 
it is necessary to recognize the existence of conceptual model of strategic planning, including the methodology of strategic planning, strategic steady "rules", organizational regulations, and the system of indicators of strategic planning of the UHSO activity. However, it is important to emphasize the "existence of the strategic directions of the UHSO development, which allow optimizing the actual expenses of boiler rooms, to carry out monitoring of the level of the equipment automation, to exercise control of high-quality regulation of loading in heating systems [12] as well as the need of application of the unified legislative base for the UHSO activity (during settlings for heat in order to avoid any divergences in settlings ), and also the need of development of other levers of the UHSO influence and the guaranteeing supplier, to consider the lack of strategic steady "rules" and presence of the strategic parameters of planning, which determine both the steady nature of the UHSO development and the existence of defective conceptual models of strategic planning.

\section{Discussion}

Nowadays in the conditions of high uncertainty of factors of the world development the activity of the Russian organizations in the branches of fuel-and-energy complex of the Russian Federation will be the subject to high risks, if the industry development strategies and the general schemes detailing them, elect not to technological improvement, but the exclusive access to the resource base as the main direction strategic orientation [13].

The document «Energy strategy of Russia until 2030" which will allow defining the purposes and problems of long-term development of branches of fuel-and-energy complex of the country for the forthcoming period, the priority directions (reference points) for the strategic planning, mechanisms of the state energy policy at separate stages of its realization, providing achievement of the named purposes of sectorial strategic planning.» General scheme of location of the energy generation facilities until 2035", which was developed according to "Rules of development and the approval of the schemes and to the programmes of perspective development of energy industry" unites some general provisions, comparing the purposes and problems of different level of management [14].

Despite the existence of legislative regulation of the general schemes and industry development strategies, the author offered to point out the following paramount reasons of updating of general schemes of location of energy generation facilities and industry development strategies of the organizations.

The possible reasons of updating of general schemes of location of energy generation facilities and industry development strategies of the organizations have to be considered in the system of strategic management of activity of the Russian organizations of fuel-andenergy complex of the Russian Federation (in this case we mean the uniform heat-supplying organizations, the heating systems and the heat-supplying organizations) and to consider the dynamic nature of the managerial process change.

The carried-out analysis allows to name some of problems of the development of general schemes of location of energy generation facilities of energy industry of the Russian Federation and the implementation of industry development strategies on the example of activity of the uniform heat-supplying organizations (UHSO).

It will be fair to mention, that in the state political system presented by some fundamental documents $[15,16,17,18]$ the close attention is paid to the problems, tendencies and the strategic directions of development of the UHSO activity, detailed in the disposal of the Government of the Russian Federation "On the Energy strategy of the Russian Federation until 2030" and the strategy of sustainable development of UHSO [16]. First, rigid periods, which became the barrier to timely and high-quality development, belong to the problems of development of general schemes of UHSO. Secondly, the existence of a large number of auditor firms and organizations performers of general schemes. Thirdly, lack of strict 
requirements to the developments of general schemes that leads to their constant quantitative, but not to high-quality growth. According to the materials of open sources, the problems of modern systems of strategic management considered on the example of large UHSO now consist of the achievement of strategic objectives of the short-term and medium-term periods and washing out of some strategic objectives of the long-term period. In the short-term period the strategic objective of the majority of UHSO is the increase in profitability at the expense of ensuring reliable and safe work of the combined heat and power plant, boiler and heating systems. In the medium-term period a strategic objective is strengthening of a financial position due to increase in profitability of operating activities, optimization of expenses and increase in economic efficiency of systems of heat supply.

\section{Conclusion}

Thus, analyzing the UHSO activity, the author revealed the lack of interrelation of elements of the system of strategic management in the long-term period as well as the lack of uniform structure of the formation of strategy for the sustainable development of UHSO. It is expedient to continue the research of the analysis of the aspects of strategic management of the UHSO activity based on the submitted analysis of some unresolved problems, as the research has scientific and debatable character.

\section{References}

1. T. Meshcheriakova, MATEC 106, 06021 (2017)

2. E. Vasilyeva, Economy and management: problems and solutions 2-4, 24-28 (2018)

3. K. Wojdyga, M. Chorzelski, Energy Procedia 116, 106-118 (2017)

4. A. Krygin, Automatic equipment and telemechanics 9, 83-102 (2010)

5. E. Gumerova, O. Gamayunova, T. Meshcheryakova, Advances in Intelligent Systems and Computing 692, 432-439 (2018)

6. M. Tyre, RES POLICY 20-1, 57-76 (1991)

7. I.V. Ilin, O.Yu. Iliashenko, A.I. Levina, Application of service-oriented approach to business process reengineering, Proc. of the 28th IBIMA Conf. - Vision 2020, pp 768781 (2016)

8. I.V. Ilin, A.B. Anisiforov, Improving the efficiency of projects of industrial cluster innovative development based on enterprise architecture model, WSEAS Transactions on Business and Economics, 11, pp 757-764 (2014)

9. V.V. Gluhov, I.V. Ilin, Lecture Notes in Computer Science, 8638, pp 509- 518, (2014) DOi-10.1007/978-3-319-10353-2_46

10. I.V. Ilin, A.I. Levina, O.Yu. Iliashenko, MATEC Web of Conf, 86, 05028 (2016) DOi - 10.1051/matecconf/20168605028

11. Ilin, O. Kalinina, O. Iliashenko, A. Levina, Procedia Engineering, Vol 165, pp 16731682 (2016) DOi - 10.1016/j.proeng.2016.11.909

12. D. Maksimova, On the matter of the current state of heat supply branch: Topical issues of scientific research (Ivanovo, Tsvetkov, 2018)

13. T. Verminskaya, V. Zinatullin, A. Kuhta, I. Rubtsov, E. Chibisova, Almanac of modern science and education 7, 37-39 (2008)

14. V. Glazkova, MATEC Web of Conferences 106, 08096 (2017)

15. News of the heat supply branch, Heat Supply News, 1(209) (2018) 
16. A. Kovalev, L. Proskuryakova, Foresight-Russia 8-3, $42-57$ (2014)

17. Power of the future for hundred years ahead, Expert 499, 37-38 (2017)

18. E. Chibisova, T. Meshcheryakova, Krasnoyarie Sceince 6(2-2), 146-148 (2017)

19. A. Bezhan, V. Minin, Thermal Engineering 64(3), 201-208 (2017) 